\title{
AUTHENTIC LEADERSHIP: A VALUE-LADEN LEADER
}

A new type of leadership that is genuine and values based laden known as authentic leadership has emerged (Zhang, Bowers, \& Mao, 2020). This form of leadership acknowledges and accommodates the legitimate needs of cultures, communities, organizations, groups and even individuals in an integrative way, rather than only being centred around organizational perspectives (Begley, 2001). George and Sims (2007, pp. 131-132) described authentic leaders as: 'develop self-awareness from their experiences; act on that awareness by practicing their values, sometimes at substantial risk; balance their motivations with both internal and external drives; keep a strong support team around themselves; and, live integrated, grounded lives'.

Early critiques to emerging authentic leadership theories described it as lacking some of the key elements of an effective leader. Particularly, it lacks focus on the leader but rather focused on the process and leadership practices a leader enacts to influence their followers (Zhang, Bowers, \& Mao, 2020). Crawford et al. (2020, p. 22) later defined authentic leaders as initials who 'influence and motivate followers to achieve goals through their sincerity and positive moral perspective, enabled through heightened awareness and balanced processing'. Other researchers concluded authentic leaders are individuals who exhibit behaviours in four ways: self-awareness; relational transparency; balanced processing; and internalized moral perspective (Shapira-Lishchinsky \& Levy-Gazenfrantz, 2016; Shapira-Lishchinsky \& Tsemach, 2014).

Kulophas et al. (2015) placed the concept of authentic leadership in an educational context. They viewed authentic school leaders as one 'who aspires to understand oneself and their teachers and behave in accordance to one's core values to steer the school towards its goals'. Authentic educational leaders focus on their self-knowledge, is sensitive to the orientations of others that leads to a synergy of leadership action (Srivastava \& Dhar, 2019). Authentic leaders have the inner ability to practice what they preach and lead their followers by setting examples (Srivastava \& Shree, 2019). Furthermore, authentic leaders are motivated to encourage their followers to become leaders in the future (Wang et al., 2014).

However, developing authenticity in a school principal is not an easy task (Srivastava \& Dhar, 2016). This is due to the school's limited context that depends on spontaneous situations to occurs in schools. Thus, developing authentic leadership in a school principal requires specific guidelines (Srivastava \& Shree, 2019). Branson (2007) stressed authentic leaders should believe in reflective practicing via analyzing and implementing their own values. This clearly indicates that authentic school leaders must adhere to their values before taking any decision (Srivastava \& Dhar, 2019). Principals should analyse the situation and implement what they believe is good for all as their decisions affect every section of the education community.

A growing body of evidences has identified principals' authentic leadership as being related to a series of school desirable outcomes such as teachers' attitude towards their profession and behaviour, more specifically, organizational citizenship and withdrawal behaviour (Shapira-Lishchinsky \& Tsemach, 2014), teacher trust (Fox et al., 2015), emotional intelligence (Shapira-Lishchinsky \& Levy-Gazenfrantz, 2016), psychological capital (Feng, 2016), academic optimism (Kulophas et al., 2018), teachers' intentions to return (Bird et al., 2012) and work engagement (Kulophas et al., 2018; Wang \& Bird, 2011). However, the body of knowledge is still relatively 
limited. Thus, researching more about how principals enact authentic leadership in schools to drive their school towards its goals is critical.

\section{REFERENCES}

Begley, P. T. (2001). In pursuit of authentic school leadership practices. International Journal of Leadership in Education: Theory and Practice, 4(4), 353-365.

Bird, J. J., Wang, C., Watson, J. \& Murray, L. (2012). Teacher and principal perceptions of authentic leadership: Implications for trust, engagement, and intention to return. Journal of School Leadership, 22(3), 425-461.

Branson, C. M. (2007). Improving leadership by nurturing moral consciousness through structured self-reflection. Journal of Educational Administration, 45(4), 471-495.

Crawford, J. A., Dawkins, S., Martin, A. \& Lewis, G. (2020). Putting the leader back into authentic leadership: Reconceptualising and rethinking leaders. Australian Journal of Management, 45(1), 114-133.

Feng, F-I. (2016). School principals' authentic leadership and teachers' psychological capital: Teachers' perspectives. International Education Studies, 9(10), 245-255.

Fox, J., Gong, T., \& Attoh, P. (2015). The impact of principal as authentic leader on teacher trust in the K-12 educational context. Journal of Leadership Studies, 8(4), 6-18.

George, B. \& Sims, P. (2007). True North: Discover Your Authentic Leadership. San Francisco, CA: Jossey-Bass.

Kulophas, D., Ruengtrakul, A. \& Wongwanich, S. (2015). The relationships among authentic leadership, teachers' work engagement, academic optimism and school size as moderator: A conceptual model. Procedia-Social and Behavioral Sciences, 191, 2554-2558.

Kulophas, D., Hallinger, P., Ruengtrakul, A. \& Wongwanich, S. (2018). Exploring the effects of authentic leadership on academic optimism and teacher engagement in Thailand. International Journal of Educational Management, 32(1), 27-45.

Shapira-Lishchinsky, O. \& Levy-Gazenfrantz, T. (2016). The multifaceted nature of mentors' authentic leadership and mentees' emotional intelligence: A critical perspective. Educational Management Administration \& Leadership, 44(6), 951969.

Shapira-Lishchinsky, O. \& Tsemach, S. (2014). Psychological empowerment as a mediator between teachers' perceptions of authentic leadership and their withdrawal and citizenship behaviours. Educational Administration Quarterly, 50(4), 675-712.

Srivastava, A. P. \& Dhar, R. L. (2019). Authentic leadership and extra role behavior: A school based integrated model. Current Psychology, 38, 684-697.

Srivastava, A. P. \& Dhar, R. L. (2016). Authentic leadership for teacher's academic optimism: Moderating effect of training comprehensiveness. European Journal of Training and Development, 40(5), 321-344.

Srivastava, A. P. \& Shree, S. (2019). Development of inclusive education theoretical model: Role of authentic leadership academic optimism and art-based pedagogies. International Journal of Educational Management, 33(6), 1271-1290. 
Wang, H., Sui, Y., Luthans, F., Wang, D. and Wu, Y. (2014). Impact of authentic leadership on performance: Role of followers' positive psychological capital and relational processes. Journal of Organizational Behavior, 35(1), 5-21.

Wang, C. \& Bird, J. J. (2011). Multi-level modelling of principal authenticity and teachers' trust and engagement. Academy of Educational Leadership Journal, 15(4), 125-147.

Zhang, S., Bowers, A. J., \& Mao, Y. (2020). Authentic leadership and teachers' voice behaviour: The mediating role of psychological empowerment and moderating role of interpersonal trust. Educational Management Administration \& Leadership, 1-18.

Donnie Adams Editor of International Online Journal of Educational Leadership Faculty of Education, University of Malaya donnieadams@um.edu.my 